\title{
The presence of an event in the narrated situation affects its availability to the comprehender
}

\author{
ROLF A. ZWAAN and CAROL J. MADDEN \\ Florida State University, Tallahassee, Florida \\ and \\ SHANNON N. WHITTEN \\ University of Memphis, Memphis, Tennessee
}

\begin{abstract}
Narrative descriptions of events often depart from how these events would have occurred in "real time." For example, narratives often contain time shifts in which events that are irrelevant to the plot are omitted. Zwaan (1996) has shown that these time shifts may affect on-line comprehension. Specifically, they are associated with increases in processing load and a deactivation of previous information. The experiments in the present article show that the situation is more complex. Specifically, there is only a deactivation of previous events if they are not assumed to be ongoing after a time shift. Furthermore, explicit discontinuations of events, as in he stopped walking also lead to deactivations when compared with explicit continuations and resumptions.
\end{abstract}

The general assumption in research on narrative comprehension is that comprehenders are influenced by the nature of the situation that is being described. The idea is that comprehenders place themselves, to some extent, "in" the narrated situation. Such a shift from an actual situation to a described situation has been termed a deictic shift (Duchan, Bruder, \& Hewitt, 1995; see also MacWhinney, 1999). As a consequence of this deictic shift, people, objects, and events that are in the narrated situation should be more accessible to comprehenders than people, objects, and events that are not. That is, nodes that code for these situational entities should be more activated when the entities are present in the situation than when they are not.

Zwaan (1999b) has reviewed various findings in the literature that are consistent with this idea. Objects that are in the situation yield shorter recognition latencies to their associated words than do objects that are not in the situation. For instance, response latencies to the word cake are faster when the text states that Mary baked cookies and cake than when the text states that Mary baked cookies but no cake, despite the fact that the word occurs in both sentences (Macdonald \& Just, 1989). This is not due simply to the presence of the word not. Kaup (1999) obtained similar effects for He destroyed the desk, but not the table. In this case, the object qualified by not was in the situation and its associated word yielded faster recognition responses. Similarly, a memory node that codes for

We thank Eileen Goodwin, Loretta Handegard, LaRicka Wingate, and Daisy Winkler for their assistance with data collection and Mike Rinck and Tom Trabasso for their helpful comments on a previous version. Address all correspondence to R. A. Zwaan, Department of Psychology, Florida State University, Tallahassee, FL 32306-1270 (e-mail: zwaan@psy.fsu.edu). an object that is close to the protagonist is more highly activated than a node that codes for an object that is distant from the protagonist (Glenberg, Meyer, \& Lindem, 1987; Morrow, Bower, \& Greenspan, 1989; Morrow, Greenspan, \& Bower, 1987; Rinck \& Bower, 1995). Furthermore, a protagonist's goal that is still active in the situation yields shorter response latencies to its associated phrase than a goal that is no longer active because it has been completed (Trabasso \& Suh, 1993; see also Lutz \& Radvansky, 1997). Findings in the realm of temporal information are also consistent with this view. When an event is present in the narrated situation, it is more accessible to the comprehender than when it is no longer going on (Anderson, Garrod, \& Sanford, 1983; Carreiras, Carriedo, Alonso, \& Fernandez, 1997; Magliano \& Schleich, 2000; Zwaan, 1996). Our present purpose is to extend these findings. In terms of Gernsbacher's (1990) structurebuilding framework, linguistic markers such as time adverbials indicating a time shift (e.g., a week later) are cues to comprehenders to refrain from mapping incoming information onto the current representation and to shift to a new substructure instead. As a consequence of the shift, information related to the previously narrated event becomes less accessible to the comprehender.

Thus far, researchers have conveyed the discontinuation of events only implicitly. For example, Anderson et al. (1983) used narratives based on scenarios such as watching a movie in the theater. The discontinuation of the scenario was implied by using a time shift that would locate the narrative "now" beyond the typical boundaries of the scenario. For instance, the time adverbial seven hours later suggests that the protagonist is no longer in the movie theater, since movies typically do not last more than two hours. In addition to time adverbials, the explicit discontinuation of an event can signal its deactivation, as in Tom 
stopped playing the piano. The deictic-shift view predicts that such an explicit discontinuation leads to a decrease in accessibility of the event in the reader's working memory; that is, the event is no longer present in the situation. This is somewhat analogous to cases in which an object is mentioned in the text although it is not present in the situation, as with the cake in Mary baked cookies but no cake. The difference is that unlike the objects, the event was present in a previous situation.

In Experiment 1, we examined the effects of explicit discontinuations of events, in conjunction with the presence or absence of time shifts, on their availability to the comprehender. In Experiments 2A and 2B, we compared the effects of explicit discontinuations of events with those of explicit continuations and explicit resumptions. In all of these cases, the deictic-shift hypothesis makes the rather straightforward prediction that events that are currently "in" the narrated situation are more accessible to the comprehender than events that are not. In order to assess availability, we collected speeded-recognition responses to probe words denoting the target events.

\section{EXPERIMENT 1}

In this experiment, we tested the effect of explicit discontinuations in conjunction with time shifts. Specifically, we used an hour later and after an hour to indicate time shifts. One of our goals was to disentangle time shifts from temporal discontinuities. A time shift occurs when the current temporal perspective, referred to as the narrative now-point (Almeida, 1995; Hopper, 1979), jumps forward or backward on the narrative timeline. A temporal discontinuity occurs when events are omitted from the narrative sequence. Often, these discontinuities are created by time shifts. For example, when we read Fred entered the building. An hour later, the phone rang, we are not privy to what went on during the previous hour. However, time shifts do not necessarily create temporal discontinuities. For example, in Fred started giving his lecture. An hour later, it started to rain, Fred is, in all likelihood, still lecturing when it starts raining. Thus, we are privy to what went on in the interim.

In Zwaan's (1996) experiments, an hour later was intended to create a time shift, but not a temporal discontinuity. Scenarios in which events that typically last more than an hour, such as a ski lesson, watching a baseball game on TV, or playing a round of golf were described. The probe words referred to aspects of these situations. For example, in the skiing scenario, it was stated that the instructor watched her pupils make curves. In this case curves was the probe word, given that make is a "light" verb and thus not very salient. Zwaan (1996) found that recognition latencies to probe words were reliably longer after the time shift of an hour than when there was no time shift, as in a moment later. This was interpreted to suggest that people do not keep track of the duration of scenarios during comprehension. However, if the comprehender is "in" the situation, the scenario should still be going on. So how can Zwaan's (1996) results be reconciled with the deictic-shift view?

We believe that Zwaan's (1996) manipulation of continuity was too coarse. For example, although the skiing lesson was still going on after an hour, and although it was very probable that the pupils were still making curves, it was possible that the instructor was not watching them at that point. Instead, it was possible that comprehenders interpreted the statement about watching the pupils make curves as an instantaneous event, rather than as an ongoing event. Consequently, an hour later, the event was no longer going on in their situation models. According to this interpretation, comprehenders monitor narrated events at a more fine-grained level. What matters is not whether an event is associated with a scenario that is still active, but whether the event itself is interpreted as still going on after the time shift. This interpretation is tentative, of course. However, it finds some support in a reanalysis of the items used by Zwaan (1996). There were three texts in which it was explicitly stated that the protagonist "started" an action (e.g., typing, watching, or talking) and in which the action verb was the probe word. These did not show a difference between the moment and hour conditions, although there was a reliable time-shift effect on recognition latencies across all texts. Thus, this informal analysis suggests that when there is a focal action that is continuous, it will remain active in the reader's mind even across a time shift. This is one of the hypotheses tested in this article. A complementary hypothesis, not tested here, but interesting for future research, is that less focal aspects of scenarios will decrease in activation after time shifts, despite the fact that they are still going on.

In Tom was playing the piano. After an hour, his mother came in, Tom is playing the piano when his mother enters the room. In contrast, in Tom stopped playing the piano. After an hour, his mother came in, he is no longer playing the piano and this has been the case for an hour. On the other hand, if hour is replaced with moment, then Tom was still playing in the was playing condition and has just stopped in the stopped playing condition. Thus, one would predict an interaction between time shift and discontinuation. Explicit discontinuations should lead to a decrease in activation. In addition, an explicit discontinuation combined with a time shift should lead to the largest decrease in activation. Thus, the following prediction about response latencies to playing can be advanced: wasmoment $=$ was-hour $<$ stopped-moment $<$ stopped-hour .

We used two different time adverbials to signal the passage of an hour: an hour later and after an hour. One reason for this was to examine whether any effects of time shifts would generalize across adverbials. If one analyzes these time adverbials semantically, a difference occurs. An hour later simply means that the currently narrated event occurred an hour later than the previously narrated event [AN-HOUR-LATER-THAN-X]; it does not imply that the previously narrated event is still going on. Thus, one can say "Tom was playing the piano. An hour later, he was 
Table 1

Probe-Recognition Latencies and Accuracy

With Standard Deviations in Experiment 1

\begin{tabular}{|c|c|c|c|c|c|c|c|c|}
\hline \multirow[b]{3}{*}{ Measure } & \multicolumn{8}{|c|}{ Condition } \\
\hline & \multicolumn{2}{|c|}{ Was/Moment } & \multicolumn{2}{|c|}{ Was/Hour } & \multicolumn{2}{|c|}{ Stopped/Moment } & \multicolumn{2}{|c|}{ Stopped/Hour } \\
\hline & $M$ & $S D$ & $M$ & $S D$ & $M$ & $S D$ & $M$ & $S D$ \\
\hline & 810 & 188 & 812 & 191 & 843 & 217 & 892 & 217 \\
\hline$\%$ correct & 94 & 10 & 95 & 9 & 95 & 9 & 96 & 8 \\
\hline
\end{tabular}

riding his motorcycle." The comprehender simply assumes that somewhere during the interval, Tom stopped playing the piano, walked over to the garage, and got on his motorcycle. On the other hand, after an hour does imply that the previously narrated event is still going on [AFTER-AN-HOUR-OF-Xing]. Thus, it would be infelicitous to say "Tom was playing the piano. After an hour he was riding his motorcycle," because there would be no time in which Tom could have gotten on his bike. The whole hour-long interval was filled with playing the piano.

However, we did not expect this difference to play a role in the present experiment, given the way our materials were constructed. Thus, we expected that after an hour would behave similarly to an hour later. That is, both adverbials should yield a time-shift effect (relative to a moment later) in the stopped condition, but not in the was condition. However, because an hour later does not presuppose a continuation, the effects might not be as clearcut in this condition as in the after an hour condition.

\section{Method}

Subjects. Forty-two undergraduate students at Florida State University participated in the experiment. Participation was part of a course requirement in psychology classes. All subjects were native English speakers.

Materials and Design. There were 36 experimental sentence pairs, each followed by a recognition probe word. The first sentence in each pair consisted of a character who either engaged in or stopped an action, as in Wayne was/stopped watching a football game. The second sentence of the pair introduced a second event that occurred either a moment later, an hour later, or after an hour. In this example, the second sentence would be "A moment later/an hour later/after an hour, he made a sandwich." The probe word was always the action word from the first sentence in the pair, in this case, "WATCHING." (See the Appendix for a sample of the stimuli used in this and the following experiments.)

This 2 (was/stopped) $\times 3$ (moment later/hour later/after hour) design yielded six within-subjects conditions. Six lists were created, such that each list contained six sentence pairs in each of the six conditions. Condition was counterbalanced across lists, such that each sentence pair occurred in a different condition on each list. Fifty filler sentence pairs were also constructed and included on each list. Probes for most of the fillers were false. That is, the probe did not occur in either of the filler sentences, although it was a related word so that the subjects could not make the recognition judgment merely on general familiarity of the probed concept. Ten such filler items served as practice trials before the remaining filler and experimental items were presented in random order. Each subject was randomly assigned to one of the six lists.

Procedure. Instructions were displayed on a computer screen, explaining that the subject was to read pairs of sentences and judge whether or not the following word had occurred in either of the two preceding sentences. The subjects were to press a key on the keyboard marked "Y" when the probe word had occurred in one of the preceding sentences and the key marked " $\mathrm{N}$ " when the probe word had not occurred in either of the preceding two sentences. The spacebar advanced the subject from sentence to sentence as well as from sentence to probe word. The subjects were asked to keep one finger on the " $\mathrm{Y}$ " key, one finger on the " $\mathrm{N}$ " key, and a thumb on the spacebar for the duration of the experiment. Once the subject understood the task, the sentences were displayed, left justified, one at a time in the center of the screen. The trials were self paced, but the subjects were told that they were being timed and were encouraged to respond as quickly as possible without compromising accuracy. Response times (RTs) and accuracy for the probe recognition task were collected. The experiment lasted approximately $20 \mathrm{~min}$.

\section{Results}

For all analyses reported, the alpha level was set at $p=$ .05 , unless otherwise noted. List will be included as a factor in the analyses of variance (ANOVAs) here only if it interacted reliably with any of the major variables (Pollatsek \& Well, 1995). Effects for the list variable are not reported, given the lack of theoretical relevance. However, whether or not list was included in the analysis is indicated by the degrees of freedom for the error term. Analyses were conducted with both variability due to subjects $\left(F_{1}\right)$ and variability due to items $\left(F_{2}\right)$ in the error term. Probe recognition latencies and accuracy scores are displayed in Table 1 . We used the following criteria to identify outliers in this and the following experiments. First, latencies of more than $3,000 \mathrm{msec}$ were removed (there were no instances of this in the present experiment). Second, we removed latencies that were more than two standard deviations from a subject's mean for that condition. In the present experiment, this resulted in the removal of less than $2 \%$ of the data.

Because our main analysis focused on the effects of the explicit discontinuation of an event (was vs. stopped) and time shift (moment vs. hour), and because we did not predict a difference between the after and later conditions, and because none was found (all $F \mathrm{~s}<1$ ), we collapsed the data across these two conditions. There was a reliable main effect for discontinuation $\left[F_{1}(1,36)=18.56\right.$; $\left.F_{2}(1,29)=13.43\right]$. The main effect of time shift was only marginally reliable for subjects and not reliable for items $\left[F_{1}(1,36)=2.91, p<.1 ; F_{2}(1,29)=2.39, p=.13\right]$. There was an interaction between these factors $\left[F_{1}(1,36)=4.88\right.$; $\left.F_{2}(1,29)=3.90, p<.06\right]$. As the averages presented in Table 1 suggest, the effect of time shift was small $(2 \mathrm{msec})$ 
Table 2

Probe Recognition Latencies and Accuracy in Experiments $2 A$ and $2 B$

\begin{tabular}{|c|c|c|c|c|c|c|c|}
\hline \multirow[b]{3}{*}{ Experiment } & \multirow[b]{3}{*}{ Measure } & \multicolumn{6}{|c|}{ Condition } \\
\hline & & \multicolumn{2}{|c|}{ Stopped } & \multicolumn{2}{|c|}{ Continued } & \multicolumn{2}{|c|}{ Resumed } \\
\hline & & $M$ & $S D$ & $M$ & $S D$ & $M$ & $S D$ \\
\hline \multirow[t]{2}{*}{ 2A (SOA $250 \mathrm{msec})$} & RT & 960 & 209 & 920 & 167 & 983 & 165 \\
\hline & $\%$ correct & 92 & 8 & 93 & 6 & 92 & 7 \\
\hline \multirow[t]{2}{*}{ 2B (SOA $1,000 \mathrm{msec}$ ) } & RT & 938 & 240 & 890 & 235 & 890 & 220 \\
\hline & $\%$ correct & 91 & 9 & 90 & 8 & 88 & 9 \\
\hline
\end{tabular}

and not reliable in the was condition (both $F \mathrm{~s}<1$ ), whereas the effect was much larger $(50 \mathrm{msec})$ and reliable in the stopped condition $\left[F_{1}(1,36)=5.95 ; F_{2}(1,29)=\right.$ 6.15]. The discontinuation effect was not reliable in the moment condition $\left[F_{1}(1,36)=2.95, p<.10 ; F_{2}<1\right]$ but was highly reliable in the hour condition $\left[F_{1}(1,36)=\right.$ $\left.29.26 ; F_{2}(1,29)=13.50\right]$. Accuracy was high and did not differ across conditions $(F \mathrm{~s}<1)$.

\section{Discussion}

These results are partly consistent with the deictic-shift hypothesis. When an event had not been in the situation for an hour, there was a decrease in the activation of that event. When, however, the event was still going on, even after a time shift, no such decrease occurred. Thus, it was not the presence of a time shift per se that led to a decrease in activation, as might be concluded from Zwaan (1996). What mattered was whether the event was still going on in the situation. In the was condition, the action was still going on, even after an hour. In the later condition, this was weakly implied by the time adverbial and inferred from world knowledge. In the after condition, it was strongly implied by the linguistic cue. In the stopped condition, on the other hand, the action had been discontinued, and the time shift now meant that it was an hour ago that the event had taken place. Thus, the event was relatively far into the past in the narrative world and was thus less accessible.

Somewhat problematic from a deictic-shift point of view is the finding that the effect of explicit discontinuations in the moment condition was only marginally reliable in the analysis for subjects and not in the analysis for items. If the event was no longer in the situation, one would expect a deactivation of that event, even if the event was discontinued only recently. We examined this issue more closely in Experiments 2A and 2B.

\section{EXPERIMENT 2A}

In this experiment, we compared the effects of explicitly stated discontinuations, continuations, and resumptions on the accessibility of events during comprehension. Experiment 1 showed that the explicit discontinuation of an event, by way of the word stopped, led to a decrease in activation for the event in question, relative to a condition in which it continued. However, this was primarily the case when there was an interval between the time at which the event was discontinued and the currently narrated event. There was no unambiguous support for the idea that explicit discontinuations lead to an immediate decrease in event availability.

In the present experiment, we examined what happens when a protagonist continues, resumes, or stops an activity after a new event that constitutes a potential interruption is described. We presented the subjects with sentence pairs such as Tom was playing the piano. When his mother entered, he stopped/continued/resumed.

The deictic-shift view makes a rather straightforward prediction regarding the activation of the target event in the stopped versus continued conditions. In the stopped condition, the activity is discontinued, whereas it is still going on, despite the intervening event, in the continued condition. Thus, the activity should be more accessible to the comprehender in the latter case than in the former. The word resumed calls for the inference that the action was momentarily stopped, presumably because of the intervening event, but is now again going on. Thus, responses to the action verb should be faster in the resumed condition than in the stopped condition.

\section{Method}

Subjects. Forty-eight undergraduate students at Florida State University participated in the experiment. Participation was part of a course requirement in psychology classes. All subjects were native English speakers.

Materials and Design. Again, there were 36 experimental sentence pairs, each followed by a recognition probe word. The first sentence in each pair introduced a character who was engaged in some activity, as in Mary was walking in the park. The second sentence of the pair introduced an intervening event, at which point the character stopped, continued, or resumed the initial activity. In this example, the second sentence would be When her friends drove by, she waved and stopped/continued/resumed. The probe word was always the action word from the first sentence in the pair, in this case WALKING (see the Appendix for sample stimuli).

In this experiment, we employed a within-subjects design with three conditions. Three lists were created, each of which contained 12 sentence pairs in each of the three conditions. Condition was counterbalanced across lists, so that each sentence pair occurred in a different condition on each list. Fifty filler sentence pairs were also constructed and included on each list. Probes for most of the fillers were false. That is, the probe did not occur in either of the filler sentences, although it was a related word so that the subjects could not make the recognition judgment merely on general famil- 
iarity of the probed concept. Ten such filler items served as practice trials before the remaining filler and experimental items were presented in random order. Each subject was randomly assigned to one of the three lists.

Procedure. The procedure was identical to that of Experiment 1, except that we collected reading times for each sentence in addition to recognition latencies and accuracy. The main reason for collecting reading times was to better assess whether the subjects were following the instructions. Furthermore, we included the presentation of a fixation point, an asterisk, which appeared immediately after the last sentence of each pair was read. The fixation point remained on the screen for $250 \mathrm{msec}$, after which the probe word appeared. The experiment lasted approximately $20 \mathrm{~min}$.

\section{Results}

The data from 4 subjects who had accuracy scores below $67 \%$ in at least one of the conditions were not included. Their accuracy scores led us to believe that these subjects had used guessing strategies at least part of the time. The data from 1 additional subject were also not included, because his/her RTs were exceedingly slow (with an average of over $2,100 \mathrm{msec}$ in the stopped condition). In some instances, the subjects did not appear to have read for comprehension, given that their reading times were below $750 \mathrm{msec}$ for one or both sentences. The recognition latencies following these reading times were excluded from further analysis. (Because reading times were not collected in Experiment 1, no such analysis could be performed there.) This involved less than $0.5 \%$ of the data. Together with the removal of outliers according to the criteria outlined above, the total of excluded data was less than $3 \%$. The results are displayed in Table 2 .

There was a main effect of condition on the recognition latencies $\left[F_{1}(2,84)=4.15 ; F_{2}(2,64)=5.59\right]$. As predicted, recognition latencies were reliably shorter in the continued condition than in the stopped condition $\left[F_{1}(1,42)=\right.$ $\left.4.54 ; F_{2}(1,32)=4.44\right]$. However, they were not reliably shorter in the resumed condition than in the stopped condition. In fact, as the averages show, the difference was in the wrong direction, although it was not significant $\left[F_{1}<1 ; F_{2}(1,32)=1.41\right]$.

\section{Discussion}

The finding that the target event was reliably more accessible in the continued than in the stopped condition is consistent with the deictic-shift view. Even after the (potentially) interrupting event was described, the target event was still more accessible when it was going on than when it was explicitly discontinued. Continued was a cue to the comprehender that the event was still going on in the situation. This provided a stronger test of the deicticshift view than did Experiment 1 because of the presence of the potentially interrupting event. It also shows that explicit discontinuations can lead to rather immediate decreases in activation of narrated events.

However, the lack of a difference between stopped and resumed was not anticipated. After all, resumed implies that the event was (after an interruption) again present in the situation. Thus, responses to the event probe should have been faster in this condition than in the stopped condition. It is instructive to compare the continued and the resumed conditions. Continued implies that the event was going on the entire time. However, resumed implies that the event was (momentarily) discontinued. This might have created an interference effect. In the resumed condition, it is implied that the protagonist stopped the activity. It is possible that the activation of this information interfered with the probe response. That is, the subjects may have just inferred that the protagonist stopped $\mathrm{X}$-ing, which then interfered with the information that the protagonist was $X$-ing, thus causing a relative delay in responses to the probe word describing the activity.

We estimated that this interference effect should wear off in about $1,000 \mathrm{msec}$. This estimate was based on Gernsbacher's work on interference in comprehension. For instance, Gernsbacher, Varner, and Faust (1990; Experiment 4) showed that skilled comprehenders show no interference from irrelevant word meanings after $850 \mathrm{msec}$ (although less skilled comprehenders still do). We assumed that by giving our subjects $1,000 \mathrm{msec}$ before making a recognition decision, we could minimize the potential interference effect. It did not seem prudent to lengthen the interval even more, because this might open the possibility for strategic responses. Therefore, we presented the probe word 1,000 msec rather than $250 \mathrm{msec}$ (as in Experiment $2 \mathrm{~A}$ ) after the last sentence of each pair was presented.

\section{EXPERIMENT 2B}

\section{Method}

Subjects. Sixty-three undergraduate students at Florida State University participated in the experiment. Participation was part of a course requirement in psychology classes. All subjects were native English speakers.

Materials and Design. The same materials and design were used as in Experiment 2A (see the Appendix).

Procedure. The procedure was identical to that of Experiment 1, except that the fixation point remained on the screen for $1,000 \mathrm{msec}$, rather than $250 \mathrm{msec}$, after which the probe word appeared immediately. RTs for the probe-recognition task were collected, as well as reading times for the second sentence, which were collected to assess whether the subjects were following the instructions. The experiment lasted approximately $20 \mathrm{~min}$.

\section{Results}

The data from 6 subjects suggested that these subjects had not followed the instructions. For 3 of these subjects, the majority of reading times were below $750 \mathrm{msec}$, suggesting that they were not reading for comprehension. Three other subjects had accuracy scores below $67 \%$ in at least one condition. All 6 subjects were excluded. Thus, the analyses were based on the data from 57 subjects. For the remaining subjects, the same criteria were used as in Experiment 2A. Probe latencies following reading times below $750 \mathrm{msec}$ were excluded from the analyses, as were outliers according to the criteria outlined earlier. In total, 
less than $3 \%$ of the data were excluded. The results are displayed in Table 2 .

There was a main effect of condition on the recognition latencies $\left[F_{1}(2,112)=3.21 ; F_{2}(2,64)=3.19\right]$. As predicted, recognition latencies were reliably shorter in the continued condition than in the stopped condition $\left[F_{1}(1,56)=4.98 ; F_{2}(1,32)=6.69\right]$ and were now reliably shorter in the resumed condition than in the stopped condition in the analysis by subjects, approaching significance in the analysis by items as well $\left[F_{1}(1,56)=4.51\right.$; $\left.F_{2}(1,32)=2.79, p<.11\right]$.

\section{Discussion}

These findings provide further support for the deicticshift hypothesis. Once again, recognition latencies were shorter in the continued condition than in the stopped condition. Moreover, they were shorter in the resumed condition than in the stopped condition, as well. This suggests, as we anticipated, that comprehenders need time to deactivate the inference that the activity was momentarily stopped. Once the interference from this inference has subsided, the renewed presence of the action in the situation provides a recognition facilitation for event probes, relative to the stopped condition in which the event is explicitly discontinued.

\section{GENERAL DISCUSSION}

These experiments provide support for the deictic-shift hypothesis. The probe-recognition latencies showed that the temporal contour of an event affects its accessibility in the comprehender's working-memory representation after a narrative time shift. If the event is no longer going on after some time has elapsed in the narrated situation, it will be less accessible than when no time has elapsed. However, if the event is (assumed to be) present in the situation even after the time shift, there is no reliable decrement in its accessibility relative to when no time has elapsed. These results show that comprehenders are not merely deactivating events in response to a time shift, as the data of Zwaan (1996) suggested. Rather, their processing is more sophisticated. Only when the event is no longer present in the situation will it be deactivated. These results are consistent with those of Zwaan (1996) in the sense that his probe words often referred to aspects of a scenario that themselves were not necessarily operative after a time shift, although the scenario that they were part of still was.

Taken together, the results provide support for the notion of a deictic shift. When readers comprehend a narrative, they place themselves "in" the situation that they are reading about. Consequently, events that are still going on in the situation are more available to the comprehender than events that are no longer going on, either because a certain amount of time has elapsed, after which it is implausible that the event is still going on (e.g., an hour later for punctual events), or because it is explicitly stated that the event is no longer going on (i.e., has stopped).

Models of situation-model construction, such as the structure-building framework (Gernsbacher, 1990) and the event-indexing model (Zwaan, 1999a; Zwaan, Langston, \& Graesser, 1995; Zwaan \& Radvansky, 1998) are in principle consistent with the idea of a deictic shift. In fact, the deictic-shift hypothesis provides an explanation for why comprehenders treat linguistic input such as time adverbials as cues to shift to a new substructure or create a new event index on the temporal dimension (see MacWhinney, 1999, for a similar but more general argument). Without a deictic-shift assumption, it would be difficult to see why temporal cues have the effects on comprehension that have been demonstrated in the literature and in our experiments. For instance, comprehenders could simply encode a proposition such as AN HOUR LATER, X, $Y$ to represent the temporal relation between events $X$ and $Y$. Without a deictic shift, there would be no reason for them to deactivate $X$ relative to a situation in which $Y$ was described as occurring a moment later than $\mathrm{X}$.

Our findings are consistent with an emerging pattern of findings in the literature, which leads to the conclusion that people, objects, events, and mental states that are currently "in" the narrated situation are more available to the comprehender than are objects, events, and mental states that are not or no longer in the situation. Speeded-recognition latencies to probe words associated with story characters no longer in the situation are longer than those to probes for characters that are still in the situation (Anderson et al., 1983). Latencies to probes for objects that are not in the described situation are longer than latencies to probes for objects that are (Macdonald \& Just, 1989). Latencies to objects distant from the protagonist are longer than those to objects close to the protagonist (Glenberg et al., 1987; Morrow et al., 1989; Morrow et al., 1987). Latencies to events no longer in the situation are longer than latencies to events that still are (Carreiras et al., 1997; Zwaan, 1996). Latencies to goals no longer operative in the protagonist's mind are longer than latencies to goals that still are (Trabasso \& Suh, 1993). The idea that comprehenders behave as though they are immersed in the narrated situation provides a coherent explanation of these findings (Zwaan, 1999b). An issue high on our research agenda is the extent to which comprehenders are immersed in narrated situations (cf. Zwaan, 1999a).

\section{REFERENCES}

Almeida, M. J. (1995). Time in narratives. In J. F. Duchan, G. A. Bruder, \& L. E. Hewitt (Eds.), Deixis in narrative (pp. 159-189). Hillsdale, NJ: Erlbaum.

Anderson, A., Garrod, S. C., \& Sanford, A. J. (1983). The accessibility of pronominal antecedents as a function of episode shifts in narrative text. Quarterly Journal of Experimental Psychology, 35A, 427-440.

Carreiras, M., Carriedo, N., Alonso, M. A., \& Fernandez, A. (1997). The role of verbal tense and verbal aspect in the foregrounding of information in reading. Memory \& Cognition, 25, 438-446.

Duchan, J. F., Bruder, G. A., \& HewitT, L. E. (1995). Deixis in narrative: A cognitive science perspective. Hillsdale, NJ: Erlbaum.

GernSBACHER, M. A. (1990). Language comprehension as structure building. Hillsdale, NJ: Erlbaum.

Gernsbacher, M. A.. Varner, K. R., \& Faust, M. E. (1990). Investigating differences in general comprehension skill. Journal of Experimental Psychology: Learning, Memory, \& Cognition, 16, 430-445. 
GlenberG, A. M., Meyer, M., \& Lindem, K. (1987). Mental models contribute to foregrounding during text comprehension. Journal of Memory \& Language, 26, 69-83.

Hopper, P. J. (1979). Aspect and foregrounding in discourse. In T. Givón (Ed.), Syntax and semantics: Vol. 12. Discourse and syntax (pp. 213-241). New York: Academic Press.

KAUP, B. (1999). Zur Verarbeitung und Repräsentation von Negation bei der Textrezeption. Unpublished dissertation, Technischen Universität Berlin.

Lutz, M. F., \& Radvansky, G. A. (1997). The fate of completed goal information. Journal of Memory \& Language, 36, 293-310.

Macdonald, M. C., \& Just, M. A. (1989). Changes in activation levels with negation. Journal of Experimental Psychology: Learning, Memory, \& Cognition, 15, 633-642.

MacWhinNeY, B. (1999). The emergence of language from embodiment. In B. MacWhinney (Ed.), The emergence of language (pp. 213 256). Mahwah, NJ: Erlbaum.

Magliano, J. P., \& Schleich, M. C. (2000). Verb aspect and situation models. Discourse Processes, 29, 83-112.

Morrow, D. G., Bower, G. H., \& Greenspan, S. L. (1989). Updating situation models during narrative comprehension. Journal of $\mathrm{Mem}$ ory \& Language, 28, 292-312.

Morrow, D. G., Greenspan, S. L., \& Bower, G. H. (1987). Accessibility and situation models in narrative comprehension. Journal of Memory \& Language, 26, 165-187.
Pollatsek, A., \& Well, A. D. (1995). On the use of counterbalanced designs in cognitive research: A suggestion for a better and more powerful analysis. Journal of Experimental Psychology: Learning, Memory, \& Cognition, 21, 785-794.

Rinck, M., \& Bower, G. H. (1995). Anaphora resolution and the focus of attention in situation models. Journal of Memory \& Language, 34, 110-131.

Trabasso, T., \& SuH, S. (1993). Understanding text: Achieving explanatory coherence through on-line inferences and mental operations in working memory. Discourse Processes, 16, 3-34.

ZWAAN, R. A. (1996). Processing narrative time shifts. Journal of Experimental Psychology: Learning. Memory, \& Cognition, 22, $1196-$ 1207.

ZWAAN, R. A. (1999a). Five dimensions of situation-model construction. In S. R. Goldman, A. A. Graesser, \& P. Van den Broek (Eds.), Narrative comprehension, causality, and coherence: Essays in honor of Tom Trabasso (pp. 93-110). Mahwah, NJ: Erlbaum

ZWAAN, R. A. (1999b). Situation models: The mental leap into imagined worlds. Current Directions in Psychological Science, 8, 15-18.

ZwaAn, R. A., Langston, M. C., \& Graesser, A. C. (1995). The construction of situation models in narrative comprehension: An eventindexing model. Psychological Science, 6, 292-297.

ZWAAN, R. A., \& RADVANSKY, G. A. (1998). Situation models in language comprehension and memory. Psychological Bulletin, 123. $162-185$.

\section{APPENDIX}

Experiment 1 Sample Stimuli

Sentence 1 Trish was/stopped tutoring the neighbors' child.

Sentence 2 A moment later/An hour later/After an hour, she broke her pencil.

Probe TUTORING

Sentence 1 Andrew was/stopped organizing his old photos.

Sentence 2 A moment later/An hour later/After an hour, he went to get the mail.

Probe ORGANIZING

Experiment 2 Sample Stimuli

Sentence 1 Thomas was programming his computer.

Sentence 2 When his drink spilled, he shrieked and stopped/continued/resumed.

Probe PROGRAMMING

Sentence 1 Mike was presenting his report.

Sentence 2 When he noticed Marsha enter the room, he glanced up and stopped/continued/resumed.

Probe PRESENTING

(Manuscript received May 24, 1999;

revision accepted for publication August 5, 1999.) 